\title{
EVALUASI PELAKSANAAN PROGRAM \\ TAMAN BACAAN MASYARAKAT (TBM) TALENTA AZZURA DI JOGOYUDAN, JETIS, KOTA YOGYAKARTA
}

\section{Tony Sunaryanta}

\begin{abstract}
This article is an evaluation result of the program implementation of TBM "Talenta Azzura" at Jogoyudan, Jetis, Jogyakarta. The evaluation was aimed at (1) community's interest on the program, (2) community as members, (3) managers and attendants, (4) support systems, (5) fund, (6) management systems, (7) services, and (8) usefulness either for its members or the community. Subjects of the evaluation were members as well as the managers and staffs of TBM "Talenta Azzura". Data were gathered through techniques of observation, interviews, questionnaires, and documentation. The analysis was conducted by using SPSS 10,00 for Window (statistical program), it was descriptive. The Evaluation model applied was Stufflebeam's CIPP (context, inputs, process, and product).

The evaluation results indicate that community has diversed socio-economic background as shown by the total income of parents ranges from Rp. 500.000,- to Rp. 750.000,-/month. Most members' parents are vendors. The questionnaires drew a conclusion that community's support quality is mediocre yet no rejection or feelings against the program. Further, conclusions drawn upon evaluation model are (1) inputs are members who age between $3-12$ years old, mostly higlymotivated girls, (2) there are two categories of the managers and staffs, permanent managers or attendants are from the community itself and there are some part-time attendants. Somehow the TBM gets little support for services and lack of fund. Results from questionnaires regarding process show low quality of management and services though data gathered regarding mentoring program indicate meaningfulness of the program for members and the community. In regards of product, results from questionnaires, interviews and observation picture that the existence of TBM is advantageous either for members or the community.
\end{abstract}

Keywords : community reading center, evaluation results, Stufflebeam's CIPP (context, input,process, product), techniques (observation, interviews, questionnaires).

\section{PENDAHULUAN}

Dalam rangka membangun sumber daya manusia yang handal dan memiliki kompetensi yang berkualitas maka kontribusi secara proposional dari masyarakat di bidang pendidikan sangat diperlukan guna mendorong masyarakat agar berprestasi secara lebih produktif untuk mencapai pembangunan nasional yang dicita-citakan. Pada seminar nasional pendidikan nonformal berbasis budaya lokal tahun 2004, Gubernur DIY menyatakan bahwa dalam evaluasi tahun 1997, kontribusi masyarakat terhadap keberhasilan pendidikan dasar di Indonesia adalah $8 \%$, sedikit lebih tinggi dari India, tetapi terlalu jauh dibanding Australia yang mencapai 40 \%. Artinya, masyarakat sebagai lingkungan belajar formal di Indonesia masih kurang memberikan dukungan prestasi belajar akademik yang berpijak pada tradisi literasi (baca-tulis). Barangkali, tradisi masyarakat cenderung lisan (pandang-dengar). Contohnya adalah waktu istirahat di kantor, terminal, sawah, bahkan di koridor perpustakaan perguruan tinggi, keadaannya seperti orang duduk-duduk mengobrol hangat, bukan tenang membaca buku (Diknas. DIY:2004).

Gaya belajar naratif atau cenderung lisan "pandang dengar" bukan sesuatu yang buruk, akan tetapi tidak cukup untuk menunjang lingkungan belajar akademik yang sangat dibutuhkan untuk keberhasilan pendidikan modern dalam memasuki zaman yang kian kompetitif. Melek huruf dalam arti luas merupakan indikator fundamental dan pintu masuk pada kualitas sumber daya manusia untuk persaingan global dan pengembangan budayanya. Kiranya diperlukan suatu transformasi kultur belajar masyarakat agar baca tulis menjadi tradisi yang kondusif bagi keberhasilan pendidikan, baik formal, nonformal, maupun informal.

Bertitik tolak dari permasalahan tersebut di atas, Direktorat Pendidikan Masyarakat memandang perlu adanya suatu perpustakaan yang bersifat nonformal yang diharapkan dapat meningkatkan minat baca masyarakat dan selanjutnya diharapkan mampu menciptakan budaya gemar belajar masyarakat dan dekat dengan lingkungan masyarakat yang kemudian dinamai Taman Bacaan Masyarakat (TBM). 
Program TBM sebenarnya telah dimulai sejak tahun 1992/1993. Program TBM ini bertujuan untuk meningkatkan minat baca dan budaya baca masyarakat, selain itu untuk meningkatkan kemampuan aksarawan baru dalam program keaksaraan fungsional dan pemberantasan buta huruf sehingga tidak buta huruf lagi. Dengan meningkatkan budaya baca masyarakat, maka tercipta masyarakat yang gemar membaca. Keberadaan TBM ini sangat penting dalam upaya membelajarkan masyarakat. Kenyataan menunjukkan, program TBM belum berhasil sebagaimana yang diharapkan, TBM masih kurang diminati warga masyarakat. Hal ini mungkin disebabkan budaya baca yang masih rendah dan belum berhasilnya pengurus dan pengelola memasyarakatkan TBM. Namun demikian, dari sekian banyak TBM, ada salah satu TBM yang menurut penulis cukup berhasil dalam mengelola, menyelenggarakan, mensosialisasikan dan mengembangkan TBM kepada masyarakat. TBM yang penulis maksud adalah TBM Talenta Azzura.

Dalam studi pendahuluan yang peneliti lakukan, diperoleh informasi bahwa pengelola TBM Talenta Azzura mengajak pihak luar untuk ikut berpartisipasi dalam memotivasi, membimbing peserta TBM dan mensosialisasikan kegiatan yang ada di TBM, sejauh mana hal tersebut mampu menarik masyarakat untuk datang dan mengapresiasi keberadaan TBM. Apakah ada dampak positif dan negatif yang ditimbulkan, masalah atau kendala apa yang dihadapi, bagaimana pengelolaannya, cara memotivasinya, pendampingannya terhadap masyarakat sehingga tujuan untuk meningkatkan minat baca dan budaya baca masyarakat dapat tercapai sesuai apa yang diharapkan yaitu meningkatnya budaya baca masyarakat dan terciptanya masyarakat yang gemar membaca.

Bertitik tolak dari uraian tersebut maka yang menjadi rumusan masalah adalah sebagai berikut. (1) Bagaimana latar belakang sosial ekonomi dan dukungan masyarakat terhadap TBM Talenta Azzura? (2) Bagaimana pengelolaan TBM Talenta Azzura? (3) Bagaimana layanan TBM Talenta Azzura? (4) Bagaimana karakteristik peserta TBM Talenta Azzura? (5) Bagaimana manfaat TBM Talenta Azzura bagi peserta dan masyarakat? Sedangkan tujuan evaluasi ini adalah sebagai berikut. (1) Memahami latar belakang sosial ekonomi dan dukungan masyarakat terhadap TBM Talenta Azzura. (2) Memperoleh informasi pengelolaan TBM Talenta Azzura. (3) Memperoleh informasi layanan TBM Talenta Azzura. (4) Mengungkap karakteristik peserta TBM Talenta
Azzura. (5) Mengetahui manfaat TBM Talenta Azzura bagi peserta dan masyarakat.

Dari tujuan tersebut manfaat yang diharapkan adalah sebagai berikut. (1) Bagi para pengambil kebijakkan, khususnya Direktorat Jenderal Pendidikan Luar Sekolah dan Pemuda, untuk dapat dijadikan masukan dalam mengembangkan TBM. (2) Bagi para pengelola TBM, hasil evaluasi dapat dijadikan bahan perbandingan tentang pengelolaan TBM. (3) Bagi orang tua dan masyarakat dapat memperoleh informasi tentang fungsi dan manfaat TBM. (4) Dalam bidang ilmu, hasil evaluasi ini diharapkan dapat memperkaya khasanah kepustakaan yang berkaitan dengan pelayanan TBM dan diharapkan dapat digunakan sebagai masukan untuk melakukan evaluasi lanjutan atau mungkin dapat dijadikan sebagai bahan perbandingan dalam evaluasi sejenis.

\section{METODOLOGI EVALUASI}

Penelitian ini bersifat evaluatif, karena tujuan kegiatan berorientasi terhadap implementasi di lapangan, yaitu bagaiman TBM Talenta Azzura menjalankan kegiatannya. Tehnik evaluasi yang digunakan adalah model Context, Input, Program, and Product (CIPP) dari Stufflebeam lihat: Soenarton, 1986 : 9; $c f:$ Worthen \& Sanders, 1987, bab 9:77-86). Model evaluasi ini berorientasi pada kebijakan (decisionoriented) yang digunakan untuk para pembuat kebijakan. Dalam hal ini, model evaluasi CIPP bertujuan untuk mengkaji peranan dan pengaruh keberadaan TBM Azzura. Berdasarkan komponennya, maka makna context terkait dengan perencaan atas keputusan yang akan diambil, misalnya perumusan tujuan. Untuk kegiatan TBM Azzura adalah sikap masyarakat terhadap TBM, pemahaman masyarakat terhadap TBM, kunjungan masyarakat ke TBM. Sedangkan input yaitu keterkaitan dari sumber-sumber dan sarana yang tersedia. Dengan demikian, dalam evaluasi ini sumber meliputi peserta, pengelola, sarana dan prasarana, serta dana. Yang dimaksud dengan process yakni kelangsungan implementasi kegiatan pengelolaan dan pelayanan TBM Azzura. Unsur product merupakan aspek keputusan daur ulang, serta hasil. Terkait dengan hal tersebut adalah pendapat anak mengenai manfaat menjadi peserta TBM, orang tua dan masyarakat mengenai manfaat program TBM bagi masyarakat. Hasil evaluasi yang diperoleh diharapkan dapat memberikan informasi untuk mendeteksi dan memberikan pertimbangan mengenai apakah ada komponen program pendidikan yang perlu diperbaiki, dimodifikasi atau mungkin 
dihentikan.

Sumber data evaluasi ini meliputi peserta Taman Bacaan Masyarakat Talenta Azzura, pengelola dan warga masyarakat. Data yang diperoleh dari peserta meliputi: karakteristik peserta, motivasi peserta, suasana, dan aktivitas peserta. Peserta adalah pengguna atau klien dari TBM Azzura, dengan demikian pendapat atau 'suara' mereka sudah sepatutnya didengar. Data dari pengelola berkenaan dengan: karakteristik pengelola, penyusunan program kegiatan, aktivitas pengelola dalam pengelolaan dan pelayanan TBM. Dalam hal ini, pengelola dapat memberi masukan mengenai faktor pendukung atau kendala yang dihadapi dalam mengelola TBM Azzura tersebut. Data dari masyarakat mengenai manfaat TBM serta data dokumentasi untuk memperkuat informasi atau mendukung data yang diperoleh dari pengguna dan pengelola.

Sesuai sumber dan jenis data yang dikumpulkan, maka teknik evaluasi yang digunakan untuk pengumpulan data dalam evaluasi ini adalah (lihat: Tuckman, 1982 : 127 - 192; Gronlund, 1985 : 323 - 407): teknik pengamatan partisipasi (participant observation), wawancara yang dilakukan kepada key informan, angket dimana lembar angket digunakan untuk mengungkap informasi dari indikator yang telah ditetapkan, kemudian dituangkan bentuk pernyataan dengan lima alternatif jawaban berupa skala ordinal, model Skala Likert dan dokumentasi yang diperoleh dari data yang ada pada pengelola yang berhubungan dengan kelengkapan administrasi kegiatan pengelolaan TBM, dari RW setempat yang digunakan untuk mengetahui keadaan penduduk setempat yang dalam hal ini adalah RW 11 yang terdiri dari RT 43, RT 44, dan RT 45 di Jogoyudan, Jetis, Kota Yogyakarta. Untuk Validitas yang digunakan dalam evaluasi ini adalah validitas isi dan untuk menguji reliabilitas digunakan rumus koefisien alfa. Koefisien reliabilitas yang dianggap layak dan memadai serta dianggap telah memuaskan bila mencapai nilai minimal 0,7. Perhatikan tabel berikut.

Tabel Teknik, Instrumen, dan Sumber Data

\begin{tabular}{|c|c|c|c|}
\hline Tehnik & Aspek Evaluasi & Instrumen & Sumber data/ subyek \\
\hline $\begin{array}{l}\text { Pengamatan } \\
\text { partisipatif }\end{array}$ & $\begin{array}{l}\text { - Sikap } \\
\text { - Perilaku } \\
\text { - Panampilan }\end{array}$ & $\begin{array}{l}\text { Lembar angket } \\
\text { pengamatan }\end{array}$ & $\begin{array}{l}\text { Pembaca/pengunjung } \\
\text { TBMAzzura }\end{array}$ \\
\hline Wawancara & $\begin{array}{l}\text { - Gagasan } \\
\text { - Pemikiran }\end{array}$ & Key informan & $\begin{array}{l}\text { - Pengelola } \\
\text { - Pengunjung }\end{array}$ \\
\hline Angket & - Sikap & Skala Likert (ordinal) & $\begin{array}{l}\text { - Pengelola } \\
\text { - Pengunjung }\end{array}$ \\
\hline Dokumentasi & Pengelolaan & $\begin{array}{l}\text {-Foto } \\
\text {-Catatan } \\
\text {-Grafik }\end{array}$ & $\begin{array}{l}\text { Kelengkapan } \\
\text { administrasi } \\
\text { pengelolaan dari RW }\end{array}$ \\
\hline
\end{tabular}

\section{HASIL EVALUASI}

\section{Latar Belakang Sosial Ekonomi Orang tua}

Latar belakang sosial ekonomi meliputi jenis pekerjaan dan tingkat penghasilan orang tua. Jenis pekerjaan akan mempengaruhi tingkat kesibukan orang tua, sedangkan penghasilan orang tua perbulan merupakan salah satu indikator terpenuhinya kebutuhan rumah tangga terutama pendidikan anak. Berdasarkan hasil penelitian, jenis pekerjaan orang tua peserta TBM dapat ditampilkan dalam Gambar 2 berikut.
Jenis Pekerjaan Orang Tua Peserta TBM

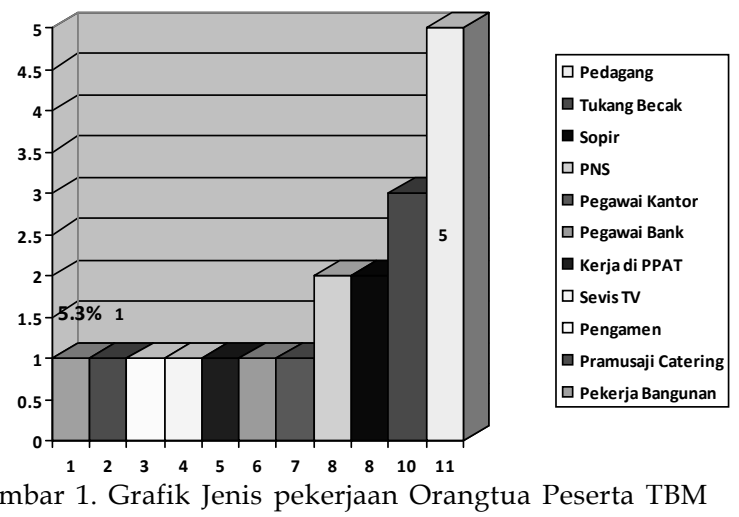


Dari Gambar 1 tersebut dapat dijelaskan bahwa jenis pekerjaan orang tua peserta TBM sebanyak 19 orang, masing-masing 1 orang $(5,3 \%)$ bekerja sebagai pekerja bangunan, pramusaji catering, pengamen, servis TV, kerja di PPAT, pegawai bank, pegawai kantor, 2 orang $(10,4 \%)$ bekerja sebagai PNS, 2 orang
$(10,4 \%)$ bekerja sebagai sopir, 3 orang $(15,8 \%)$ bekerja sebagai tukang becak, 5 orang $(26,3 \%)$ bekerja sebagai pedagang.

Latar belakang sosial ekonomi yang berupa tingkat penghasilan perbulan orang tua dapat ditampilkan pada Gambar 3 berikut ini:

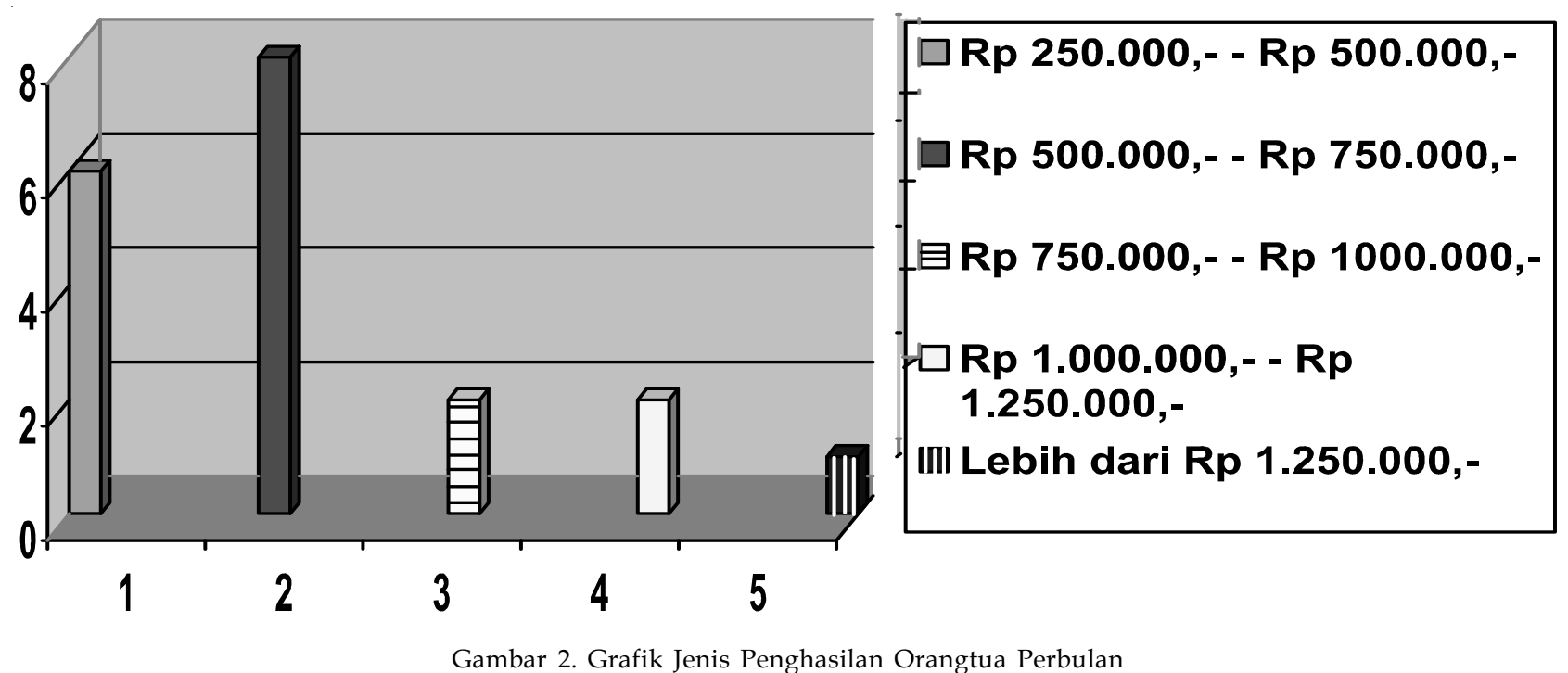

Dari Gambar 2 tersebut dapat dijelaskan bahwa penghasilan per bulan orang tua peserta TBM. Sebanyak 6 orang $(31,6 \%$ ) berpenghasilan Rp.250.000 - Rp.500.000, 8 orang (42,1\%) berpenghasilan Rp.500.000 - Rp.750.000, 2 orang (10,5\%) berpenghasilan Rp.750.000 - Rp.1.000.000, 2 orang (10,5\%) berpenghasilan Rp.1.000.000 - Rp.1.250.000, dan 1 orang (5,3\%) berpenghasilan di atas Rp. 1.250.000.

\section{Dukungan Masyarakat terhadap TBM Talenta Azzura}

Dukungan dalam bentuk dorongan kepada putra-putrinya untuk mengikuti TBM Talenta Azzura cukup besar, bahkan diakui oleh beberapa peserta meskipun hari hujan tetap disuruh berangkat. Dari hasil wawancara dengan salah satu orangtua peserta yaitu bapak Sriyono diketahui bahwa dukungan itu disebabkan karena orangtua merasa tidak punya waktu dan kurang bisa mengajari pelajaran di rumah.

\section{Input}

\section{Peserta TBM Talenta Azzura}

Peserta TBM Talenta Azzura sebagian besar adalah anak-anak, dengan rentang usia 3 tahun sampai dengan 12 tahun. Sedang berdasarkan jenis kelamin, maka peserta TBM Talenta Azzura sebagian besar adalah wanita. Untuk rentang pendidikan sebagian besar peserta adalah murid SD dari kelas 1 sampai dengan kelas VI dan sebagian kecil ada yang masih pra TK dan TK. Motivasi anak menjadi pesertai TBM Talenta Azzura berdasarkan hasil evaluasi, ternyata termasuk tinggi. Hal ini terjadi karena anak yang mengikuti kegiatan menganggap bahwa TBM Talenta Azzura selain tempat untuk berkumpul dan membaca, juga sebagai tempat bimbingan belajar terutama untuk membantu mengerjakan PR.

Dari hasil observasi diketahui bahwa sebagian besar anak-anak datang ke TBM Talenta Azzura karena keinginan sendiri, biasanya anak yang datang karena keinginan sendiri mempunyai keinginan kuat untuk belajar dan membaca buku. Temuan menarik lain dari observasi adalah kedatangan anak yang lebih awal dari waktu yang telah dijadwalkan. Bahkan jika hari hujan, mereka tetap menunjukkan semangat yang sama, yaitu datang ke TBM Talenta Azzura lebih awal.

\section{Pengelola}

Di TBM Talenta Azzura peran pengelola dalam kegiatan TBM dirasa masih kurang. Salah satunya disebabkan karena pengelola TBM belum pernah mengikuti pelatihan tentang TBM ataupun tentang perpustakaan, padahal pengetahuan dan keterampilan mengenai TBM penting untuk dipahami secara menyeluruh oleh pengelola agar pengelola dapat menjalankan program kegiatan dan pengelolaan dengan baik dan benar. Pemahaman pengelola dalam pengelolaan TBM yang kurang akan menyebabkan pengelola tersebut tidak dapat memberikan kontribusi yang optimal dalam penyelenggaraan kegiatan TBM, bahkan sangat mungkin dapat menghambat kelancaran pelaksanaan kegiatan.

Selain pelatihan, diperlukan juga pengalaman bersosialisai dengan anak, hal ini untuk memahami 
apa yang sebenarnya dibutuhkan dan dimaui oleh si anak. Semakin jarang intensitas pertemuan dengan anak, maka wawasan pengelola tentang anak kurang berkembang. Oleh karena itu di TBM Talenta Azzura kemudian diadakan pendampingan untuk pelaksanaan kegiatan di TBM. Sayangnya peran pendampingan dan ketrampilan mengelola TBM ini masih dilakukan oleh pihak luar yaitu mahasiswa KKN dan belum dilakukan oleh warga masyarakat.

\section{Sarana dan Prasarana}

Berdasarkan hasil observasi, belum semua kebutuhan sarana dan prasarana yang dibutuhkan untuk penyelenggaraan TBM terpenuhi, bahkan dapat dikategorikan kurang. Sebagai contoh ruang baca, ruang administrasi bahkan rak khusus bukupun belum tersedia, padahal ketiga fasilitas tersebut memegang peranan yang cukup penting dalam kegiatan penyelenggaraan TBM. Fasilitas lainnyapun ketersediaannya tidak dalam kondisi yang memadai.

Untuk buku bacaan, yang biasa ada di TBM Talenta Azzura ada sekitar 75 buah, terdiri dari buku cerita anak, buku agama, buku pelajaran, komik, majalah anak dan buku umum yang masih menyangkut dunia anak. Setiap satu bulan buku tersebut dirotasi dengan buku lainnya yang ada di Wacana yang saat ini juga bekerjasama dengan perpustakaan keliling mabulir. Keadaan buku yang ada dari hasil observasi ternyata masih utuh dan bagus, hal ini ternyata karena buku-buku yang sudah tidak layak pakai biasanya tidak diedarkan untuk kemudian dijual kiloan, dan uang hasil penjualan biasanya digukan lagi untuk membeli buku yang baru. Rotasi buku ternyata sangat bagus untuk mempertahankan dan menumbuhkan minat baca peserta TBM Talenta Azzura, karena biasanya anak hanya akan mau membaca maksimal dua kali saja dan setelah itu tidak membaca buku yang sama lagi, hal inilah yang menjadi salah satu alasan TBM Talenta Azzura bekerjasama dengan Wacana yang memang peduli dengan usaha untuk menumbuhkan dan mengembangkan minat baca menuju masyarakat gemar membaca.

\section{Dana}

Selama ini untuk penyelenggaraan kegiatan TBM Talenta Azzura, dana didapat dari swadaya masyarakat setempat, masyarakat umum bahkan pendamping juga mencari dana misalnya dengan mengamen. Hal yang perlu menjadi perhatian, dana tersebut baru akan diminta apabila TBM Talenta Azzura membutuhkan sesuatu yang memerlukan dana, ini menyebabkan dana yang didapat hanya sebatas kebutuhan yang mendesak dan jumlahnya relatif kecil. Akibatnya dana tidak secara rutin didapat dan kadang kurang untuk kegiatan TBM Talenta Azzura. Ini berarti belum ada sistem perolehan dana yang tetap, oleh karena itu perlu adanya sebuah perencanaan yang matang mulai dari sumber dana yang jelas, transparansi penggunaan uang, serta rencana kegiatan yang jelas, sehingga pihak donor yakin akan kegunaan uang yang telah diberikan dan diharapkan dapat memberikan dana secara rutin.

\section{Process}

1. Aktivitas Pengelolaan

Pengelola TBM Talenta Azzura belum pernah mengikuti pelatihan tentang cara pengelolaan TBM Talenta Azzura. Dengan demikian, sebenarnya para pengelola belum mengetahui cara mengelola TBM Talenta Azzura secara menyeluruh, hal ini akan menyebabkan pengelola tersebut tidak dapat memberikan kontribusi yang optimal dalam penyelenggaraan kegiatan TBM Talenta Azzura.

Pengelolaan TBM Talenta Azzura yang meliputi koleksi buku, administrasi TBM Talenta Azzura belum terlaksana dengan baik, bahkan pengelola sering tidak hadir. Hal ini terjadi selain karena status pengelola adalah sukarela sehingga merasa tidak terikat, juga disebabkan karena sarana dan prasarana yang kurang memadai. Pengadaan dan pemeliharaan koleksi sarana buku yang ada di TBM Talenta Azzura juga cukup memprihatinkan, karena ternyata buku yang merupakan buku milik sendiri hanya ada sekitar 40 buah buku dan itu pun sebagian besar sudah termasuk buku usang sedangkan untuk penambahan koleksi belum dilakukan

\section{Aktivitas Pelayanan}

Untuk mengatasi hal tersebut TBM Talenta Azzura melakukan kerjasama dengan LPM USD berupa pendampingan yang dilakukan melalui KKN alternatif. Pendampingan kegiatan berlangsung $3 \mathrm{kali}$ dalam seminggu. Adapun kegiatan pendampingannya secara garis besar meliputi kegiatan membaca mandiri, bimbingan belajar, menggambar, seni melipat kertas dan pemahaman bacaan ataupun cerita. Dalam kegiatan membaca mandiri, pembimbing bertanggung jawab memilihkan koleksi buku yang cocok dengan kebutuhan anak, ini bukan merupakan sesuatu yang mudah untuk dilakukan, karena meskipun menarik untuk dibaca namun bila tidak sesuai dengan kebutuhan maka buku bukannya meningkatkan minat baca dan pengetahuan namun justru merusak mental anak. Oleh karena itu pemilihan buku yang baik selalu dilakukan oleh pendamping. Juga dalam jumlah dan jenis buku, maka kemudian diadakan rotasi buku dengan cara bekerjasama dengan Wacana dan Mabulir.

Perspektif Ilmu Pendidikan - Vol. 15 Th. VIII April 2007 
Setelah buku dipilih pendamping maka kemudian dipinjamkan untuk dibaca dan nanti bila ada hal yang kurang jelas maka pendamping akan menjelaskannya. Demikian pula dengan kegiatan bimbingan belajar, pembimbing akan membantu menyelesaikan masalah belajar anak, yaitu membantu menyelesaikan pekerjaan rumah. Kegiatan yang lain adalah pengenalan lingkungan, pengenalan lingkungan dimaksudkan agar ada interaksi antara anak dengan lingkungan sosialnya dan lingkungan hidup. Cara yang dilakukan adalah anak diajak jalanjalan di sekitar kampungnya dan menyapa serta berbicara dengan orang-orang yang ditemuinya, sambil mencatat segala sesuaitu yang ada disekitarnya, misalnya jumlah pohon dan nama pohon yang ditemukannya. Dan setelah kembali diminta menceritakan kesan dan pengalamannya serta mendiskusikannya.

Untuk lebih meningkatkan komunikasi dan anak lebih merasa diperhatikan, ada satu kegiatan yang menurut anak-anak sangat berkesan, yaitu merayakan ulang tahun dan memberi sekedar hadiah kepada anak yang saat itu sedang berulang tahun. Hal ini sering tidak disangka oleh anak itu sendiri karena belum pernah merayakan ulang tahunnya, bahkan ada yang menangis karena sangat bahagia mendapat ucapan ulang tahun dan kemudian menyanyikannya.

\section{Product}

\section{Manfaat peserta TBM Talenta Azzura}

Manfaat yang didapat oleh peserta TBM Talenta Azzura meliputi manfaat kegiatan membaca mandiri, bimbingan belajar, menggambar, origami, dan pemahaman bacaan/cerita buku. Kegiatan pendampingan yang telah dilakukan kepada peserta berperan besar terhadap tingginya manfaat yang dirasakan oleh peserta, hal ini karena terjalinnya interaksi yang baik antara peserta dan pendamping sehingga menurut hasil wawancara kegiatan ini menjadi sangat menyenangkan, akrab, dan anak merasa diperhatikan. Untuk lebih meningkatkan manfaat yang diperoleh peserta, tentunya akan lebih baik apabila kerjasama yang dilakukan lebih ditingkatkan dan kekurangan dana serta sarana dan prasarana yang ada dapat sedikit demi sedikit teratasi.

2. Manfaat TBM Talenta Azzura bagi Masyarakat

Kegiatan tersebut sangat bermanfaat bagi masyarakat, terutama beban dari orang tua peserta apabila harus mendampingi mengerjakan pekerjaan rumah, karena merasa berat dan sulitnya mata pelajaran anak saat ini serta sempitnya waktu luang dari orang tua. Selain itu anak juga dapat membaca buku, komik, majalah anak secara gratis serta mendengarkan cerita dari kakak pembimbing. Kegiatan lomba di lapangan juga disenangi warga masyarakat karena merupakan hiburan tersendiri.

Jadi sebenarnya manfaat keberadaan TBM Talenta Azzura telah dirasakan oleh warga masyarakat, hanya saja manfaat yang ada belum bisa menggerakkan partisipasi aktif masyarakat terhadap TBM Talenta Azzura, hal inilah yang perlu lebih digairahkan dengan cara saling mendekatkan diri antara TBM Talenta Azzura dan masyarakat dengan bantuan pengurus RW, pengelola dan pendamping itu sendiri.

\section{HASIL PENELITIAN}

1. Program TBM Talenta Azzura ini dilaksanakan di daerah yang pendapatannya tergolong rendah, namun mereka mendukung adanya program TBM Talenta Azzura.

2. Dukungan masyarakat cukup baik, meskipun terlaksananya penyelenggaraan TBM Talenta Azzura lebih besar dukungannya dari lembaga luar yaitu dari wacana dan mahasiswa KKN

3. Pengelola TBM Talenta Azzura belum pernah mengikuti pelatihan tentang cara pengelolaan TBM Talenta Azzura. Dengan demikian, sebenarnya para pengelola belum mengetahui cara mengelola TBM Talenta Azzura secara menyeluruh, hal ini akan menyebabkan pengelola tersebut tidak dapat memberikan kontribusi yang optimal dalam penyelenggaraan kegiatan TBM Talenta Azzura.

4. Pengelolaan TBM Talenta Azzura yang meliputi koleksi buku, administrasi TBM Talenta Azzura belum terlaksana dengan baik, bahkan pengelola sering tidak hadir. Hal ini terjadi selain karena status pengelola adalah sukarela sehingga merasa tidak terikat, juga disebabkan karena sarana dan prasarana yang kurang memadai.

5. Dari hasil pengamatan, dalam hal pelayanan, waktu layanan sesuai yang direncanakan yaitu tiga kali dalam seminggu, jam buka dan tutup cukup tepat dari jam 15.30 WIB -17.30 WIB dan waktu peminjaman selama dua hari ditepati oleh peminjam. Untuk peminjaman saat ini maksimal dua buku, dengan jenis buku yang telah diseleksi oleh pendamping. Untuk ruang baca masih memprihatinkan karena sebagian besar masih menggunakan alas tikar dan lampu kurang terang.

6. Tenaga Pelayanan yang ada di TBM Talenta Azzura dari pengurus warga RW 11 sering tidak 
hadir, sedangkan dari pihak luar selalu datang yang kegiatan berupa pendampingan yang secara garis besar meliputi kegiatan membaca mandiri, bimbingan belajar, menggambar, seni melipat kertas, dan pemahaman bacaan ataupun cerita. Kegiatan pendampingan yang lain adalah pengenalan lingkungan, pengenalan lingkungan dimaksudkan untuk supaya ada interaksi antara anak dengan lingkungan sosialnya dan lingkungan hidup. Dari kegiatan pendampingan tersebut terjalin interaksi yang baik antara pengelola dan peserta.

7. Peserta TBM Talenta Azzura adalah anak- anak TK dan SD dengan usia 3 - 12 tahun dan sebagian besar adalah wanita.

8. Keberadaan TBM Talenta Azzura di daerah Jogoyudan dirasakan manfaatnya baik oleh peserta TBM Talenta Azzura maupun masyarakat sekitar TBM Talenta Azzura, namun hal ini belum dapat menumbuhkan partisipasi aktif dari masyarakat.

\section{DAFTAR PUSTAKA}

Dinas Pedidikan. (2004). Refleksi strategi budaya dalam pengembangan pendidikan nonformal menuju sdm berkualitas. Yogyakarta: Tim Penulis.
Direktorat Pendidikan Masyarakat. (2003). Pedoman pengelolaan taman belajar masyarakat. Jakarta: Ditjen Diklusepa Depdiknas.

Gronlund, N.E. (1985). Measurement and evaluation in teaching $\left(5^{\text {th }}\right.$ ed). New York - London : MacMillan Publishing Co. \& Collier MacMillan Publ.

Heineke, W \& Jerry W. (eds., 2001). Methods of evaluating educational technology. Greenwich, Conn : Information Age Publ.

Soenarto. (1986). Berbagai model evaluasi program. Makalah disajikan pada Penataran Metodologi Evaluasi bulan Oktober 1986. Yogyakarta: Lembaga Evaluasi IKIP Yogyakarta

Tuckman, B.W. (1982). Conducting Educational Research $\left(2^{\text {nd }}\right.$ ed). New York: Harcourt, Brace, Jovanovich, Inc.

Worthen, B. R. \& James R.S. (1987). Educational evaluation: Alternative approaches and practical guidelines. New York \& London : Longman.

\section{KETERANGAN PENULIS}

Ir. Tony Sunaryanta, M.Pd., dilahirkan di Bantul, Desember 1968. Saat ini menjabat sebagai pamong belajar muda di kota Yogyakarta. Telah menyelesaikan program pendidikan pasca sarjana UNY dan salah satu karya ilmiah yang sudah dihasilkan antara lain mengenai Peran PKBM dalam pengembangan personal dan sosial masyarakat pada Desember 2005. 